
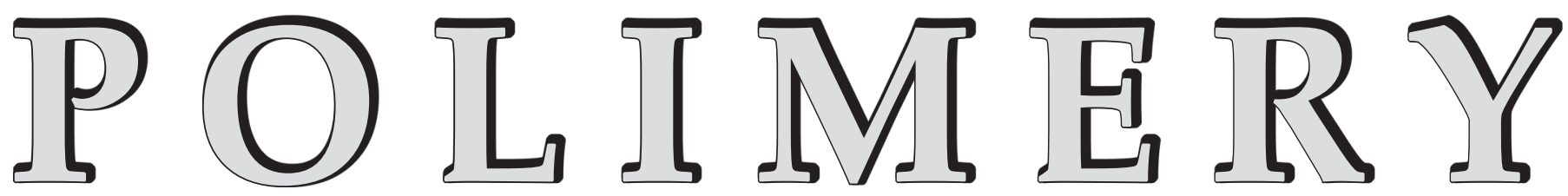

\title{
Coloration of poly(lactic acid) based textiles - a review
}

\author{
Gulzar Ahmad Baig1) \\ DOI: dx.doi.org/10.14314/polimery.2020.6.1
}

\begin{abstract}
Polyester fibers include industrially important cellulose acetate, poly(ethylene terephthalate) (PET), poly(1,4-cyclohexane dimethylene terephthalate) (PCDT), poly(trimethylene terephthalate) (PTT), poly(lactic acid) (PLA) fibers; however, it is the last one that has been considered to be a "green" one. PLA is an eco-friendly polyester material that is obtained from renewable resources. The effect of chromophoregens and substituents on exhaustion, colorimetric and fastness properties of PLA with newly developed disperse dyes has been outlined. The differences in colorimetric properties, wavelength-shift and deep-dyeing behavior of PLA as compared to PET have been explained. Use of non-aqueous dyeing media such a super critical carbon dioxide $\left(\mathrm{sc}^{-} \mathrm{CO}_{2}\right)$, various organic solvents and carriers have been discussed.
\end{abstract}

Keywords: PLA, sustainable and biodegradable, dyeing and printing, fastness properties, fiber treatments, environmental impact.

\section{Barwienie tkanin na bazie poli(kwasu mlekowego) - przegląd}

Streszczenie: Ważne dla przemysłu włókna poliestrowe bazują na: octanie celulozy, poli(tereftalanie etylenu) (PET), poli(tereftalanie 1,4-cykloheksanodimetylenu) (PCDT), poli(tereftalanie trimetylenu) (PTT) i, ostatnio uznanym za "zielony", poli(kwasie mlekowym) (PLA). PLA to ekologiczny materiał poliestrowy pozyskiwany z zasobów odnawialnych. W artykule omówiono wpływ chromoforegenów i podstawników obecnych w cząsteczkach nowo opracowanych barwników dyspersyjnych na właściwości zmęczeniowe, kolorymetryczne i trwałość barwionych włókien PLA. Wyjaśniono różnice we właściwościach kolorymetrycznych, przesunięciu długości fali i głębokości zabarwienia PLA i PET. Przedstawiono zastosowanie $\mathrm{w}$ procesie barwienia włókien PLA niewodnych środków barwiących, takich jak: nadkrytyczny ditlenek węgla (sc- $\left.\mathrm{CO}_{2}\right)$, różne rozpuszczalniki organiczne i nośniki.

Słowa kluczowe: PLA, zrównoważony i biodegradowalny, farbowanie i drukowanie, właściwości wytrzymałościowe, obróbka włókien, wpływ na środowisko.

Poly(lactic acid) or polylactide (PLA) (the name depends on obtaining method) is a biodegradable and sustainable polyester that is considered to have the potential of replacing PET [poly(ethylene therephthalate)] fibers. Schematic chemical structure of PLA is shown in Formula (I). The

\footnotetext{
1) University College of Textile Engineering, Bahauddin Zakariya University Multan, Pakistan.

e-mail: gabaig@bzu.edu.pk
}

alternate up and down positions of carbonyl groups show that the structure is helical. The ester linkage is the characteristic of polyesters [1]. Its raw material is obtained from renewable crops such as corn. PLA is a thermoplastic polyester, it has poor hydrolytic and thermal stability as compared to industry - standard PET and doesn't always perform well during dyeing. An understanding of fiber behavior during various physical and chemical processes is essential to design textile processes that assure quality 
with maximum structural integrity of PLA. Finding the best process conditions and methods for wet processing and after-care applications for PLA-based textile products will certainly increase the performance of PLA. It is important to redesign the existing pretreatment dyeing and finishing processes keeping in view the physical and chemical properties of PLA fibers. The pretreatment conditions and their effect on absorbency, whiteness and mechanical properties have been well documented [2-5].<smiles>CC(O)OC(=O)C(C)OC(=O)C(C)OC(=O)C(C)O</smiles>

\section{Formula (I)}

Being a polyester, disperse dyes are ideal candidates for dyeing poly(lactic acid) (PLA). However unlike PET, the recommended dyeing conditions for PLA are $110^{\circ} \mathrm{C}$ and $\mathrm{pH} 4.5-5$ for $30 \mathrm{~min}$ [6]. The dyeing of PLA at lower temperature as compared to PET is due mainly to poor hydrolytic stability of the former at high temperature particularly when processed for extended time, the latter being simulated as multiple dye-additions [1]. An associated potential problem of dyeing at low temperature may be the low exhaustion of disperse dyes, poor levelling and process inefficiency. When cellulose acetate fibers were introduced no dyes existed to satisfactorily color them. Therefore, different approaches were adopted to sort out the problem. In one approach existing dyes were chemically modified to render them temporarily soluble in aqueous medium. These solubilized dyes were then hydrolyzed during the course of dyeing converting them back to their insoluble form thus making the dyeing a success. In addition to the developments of new disperse dyes designed especially for cellulose acetate fibers, a new dyeing method, known as carrier dyeing, was also established which greatly enhanced dyeing efficiency and commercialization. Solvent dyeing of polyester fibers was also introduced, as an alternative to aqueous dyeing system, in which dyeing was carried out in suitable organic solvents. The modern development is using super critical carbon dioxide $\left(\mathrm{sc}-\mathrm{CO}_{2}\right)$ as the medium of dyeing polyester fibers with disperse dyes. All of the above methods, once again, are being investigated to color PLA with existing disperse dyes.

General reviews on the lactic acid monomers and manufacturing, pretreatments, dyeing, finishing and after-treatments of PLA have been presented in the past $[7,8]$. However, none of the reviews focused the dyeing of PLA based textiles. In an attempt to review progress in the coloration of PLA fibreers, yarns and fabrics, the present review discusses major developments till now. The last section discusses state-of-the-art technologies and potential ideas that may solve issues confronting PLA processing.
This review article has been written with material taken from renowned textile and related journals. Major publisher databases viz., Springer, Taylor \& Francis, Wiley, SAGE journals, Elsevier and ScienceDirect were searched for keywords such as: PLA, PLA dyeing and biodegradable fibers for peer reviewed articles in English. The relevant studies published from 2000 till now were selected and further scrutinized based on relevant material. A total of two-hundred research publications were collected out of which only eighty eight, the most relevant, were short listed. Though pre-treatments are essential unit operations in achieving solid and spatially uniform colors with good dye exhaustion, the present review didn't include them except clearing-off which had been considered as an essential part of dyeing. The articles discussing only the coloration were reviewed. The paper introduces the dyeing of PLA with various classes of dyes, the colorimetric and fastness properties, dyeing technologies, etc. A valuable part of the review is the future trends that discuss the possible solutions to the problems and areas where further research may be carried out.

\section{COLORATION OF POLY(LACTIC ACID)}

The existing disperse dyes have been designed and optimized for PET fibers, and therefore they may not exhibit the same level of buildup, performance and fastness properties on PLA. It is important to note that there do not exist any universal dye range of disperse dyes that can dye all the polyesters. There are separate disperse dye ranges for cellulose acetate and PET and most likely dyes shall have to be tailored for PLA fibers as well.

\section{Disperse dyes}

Disperse dyes are non-ionic aromatic compounds that can modify the visual appearance of textiles through selective absorption of light. Based on the principle of "like-dissolves-like", these non-polar hydrophobic dyes have substantivity for most of the synthetic fibers such as nylons, acrylics and polyurethanes though polyester fibers viz., PET, PCDT \{poly[(1, 4-cyclohexylene-dimethylene)terephthalate]\}, PLA and cellulose acetates are exclusively dyed with disperse dyes. Though practically insoluble in water, disperse dyes do have limited solubility $\left(0.3-7.1 \mathrm{mg} / \mathrm{dm}^{3}\right.$ at $\left.25^{\circ} \mathrm{C}\right)$ due to the presence of polar chemical groups, the solubility increasing with increase in temperature. For good diffusion, dye structures should be as compact and planar as possible so that they find little difficulty in penetrating into the amorphous matrix of the fiber. The stereo-chemical structures of the dyes have important influence on the exhaustion and substantivity of the dyes on fiber.

Research undertaken at DyStar showed that mediumenergy disperse dyes exhibited high exhaustion levels while low- and high-energy disperse dyes gave low levels of exhaustion [6]. It was claimed that disperse dyes 
with compact and linear structures must be used for PLA dyeing since crystallinity of fiber inhibited dye diffusion. It was observed that dyes containing multiple carbonyl $(>C=O)$ groups didn't exhaust well on PLA. Therefore, disperse dyes with carbonyl groups and anthraquinone (AQ) dyes should be avoided. Liang et al. applied various substituted AQ disperse dyes on PLA and reported that dyes containing alkyl chains, opposed to aromatic rings, exhibited better exhaustion, however, too long alkyl chains led to diffusion and poor exhaustion problems. The exhaustion increased up to $(96.3 \%)$ for $-\left(\mathrm{CH}_{2}\right)_{5} \mathrm{CH}_{3}$ group and then decreased [9, 10]. Karst and Yang tried to explain exhaustion of disperse dyes on PLA using the concept of solubility parameter and claimed that dyes with solubility parameters close to $20.2\left(\mathrm{~J} / \mathrm{cm}^{3}\right)^{0.5}$ exhibited high exhaustion on PLA [11]. Disperse dyes with solubility parameters $<25.0\left(\mathrm{~J} / \mathrm{cm}^{3}\right)^{0.5}$ exhibited more than $70 \%$ exhaustion on PLA [at $2 \%$ o.w.f. (on-weightof-fiber)]. They proposed general structures for disperse dyes that could be developed and may have high exhaustion on PLA. It was stated that most of the disperse azo dyes had solubility parameters close to that of PLA with some other dyes that contained more $-\mathrm{NR}_{2}$, $-\mathrm{NHCOR}$, -NHR, -COR, -OR, or -COOR groups than $-\mathrm{NO}_{2},-\mathrm{NH}_{2^{\prime}}$ $-\mathrm{OH},-\mathrm{CN}$, halides $(-\mathrm{X})$ and hydrocarbon groups such as $-\mathrm{CH}_{3^{\prime}}-\left(\mathrm{CH}_{2}\right)_{n} \mathrm{CH}_{3^{\prime}}$ or a phenyl. The solubility parameters of most of the AQ dyes were not close to that of PLA. Though AQ dyes didn't have solubility parameters close to that of PLA, they might have if they contain linear alkyl groups. Using molecular modelling techniques, Karst et al. calculated interaction energies between PLA-dye systems and plotted against sorption [12]. A linear relationship was found between percent sorption vs. dye-fiber interaction energies with the predicted sorption values agreeing with the calculated values. It was shown that within a single dye the following groups formed strongest interactions $-\mathrm{N}\left(\mathrm{C}_{2} \mathrm{H}_{4} \mathrm{OCOCH}_{3}\right)_{2^{\prime}}$ $-(\mathrm{CO})_{2} \mathrm{NC}_{3} \mathrm{H}_{6} \mathrm{OCH}_{3^{\prime}}-\mathrm{SO}_{2} \mathrm{NHC}_{6} \mathrm{H}_{5^{\prime}}-\mathrm{NO}_{2^{\prime}}, \mathrm{CN}(\mathrm{NH}) \mathrm{C}_{6} \mathrm{H}_{4^{\prime}}$ $-\mathrm{CH}(\mathrm{CO})_{2} \mathrm{C}_{6} \mathrm{H}_{4}$ while the groups that formed the weakest interactions were $-\mathrm{Br}$ and $-\mathrm{Cl}$. He et al. investigated the dyeing behavior of polylactide fibers for 1-phenyl-3-methyl-5-pyrazolonyl azo- anthraquinone disperse dyes. It was concluded that dyes could be applied at low temperature and exhibited good fastness properties [13]. Liang et al. prepared azo-anthraquinone disperse dyes by combining the substantive features of 1-aminoanthraquinone and good light fastness of phenylpyrazolone systems [13]. It was reported that the optimum dyeing conditions for PLA were $90^{\circ} \mathrm{C}, \mathrm{pH} 5.0$ and $60 \mathrm{~min}$ and that the resultant dyeings exhibited moderate to good wash fastness which were comparable to PET. On Blue Wool Scale, the light fastness on PET and PLA were 6 and 7, respectively. Choi et al. 2010 investigated the effect of various substituents on the dyeing properties of azo dyes derived from $N$-alkyl phthalimide [14]. It was reported that good ratings for dyeings suggest that phthalimidazo system might be of interest in developing high wash fast disperse dyes for PLA. Hansakulwat et al. dyed PLA with a reactive-disperse dye based on sulfatoethyl sulfone and reported excellent performance and fastness properties [15]. Cui et al. investigated the effect of alkyl substituents on the exhaustion of sulfonamide containing orange phenylazo- $\beta$-naphthol disperse dyes on PLA [16]. It was reported that dyes that contained sulfonamide groups bearing linear tertiary alkyl chains exhibited good substantivity and high exhaustion. The dye that contained $N, N^{\prime}$-butylsulfonamide group had the lowest aqueous solubility with the highest exhaustion of $98.6 \%$ at $2 \%$ o.w.f. shade depth. Cui et al. also prepared and investigated the spectral and dyeing properties of nine phenylazopyrazolone-containing acylamide disperse dyes on PLA [17]. It was reported that introduction of tertiary acylamide groups substituted with linear saturated alkyl chains into phenylazopyrazolone chromophores resulted in improved dye sorption and fastness properties on PLA fabric. It was argued that the existence of polar acylamide group in the dye molecule and their suitable water solubility offered them higher affinity to PLA. Among the nine dyes, the dye with $n$-butyl substituted acylamide group yielded the best dyeing performances on PLA fabric with over $95 \%$ dye sorption at $110^{\circ} \mathrm{C}$ and satisfactory color fastness properties. Lihua et al. synthesized five yellow azo-anthraquinone disperse dyes containing different alkyl substituents on the phenyl alkyl-sulfonamide [18]. Artificial intelligence-based molecular modelling revealed that $\log \mathrm{P}$, molecular volume and planar shape increased with increasing alkyl chain length. Lu et al. synthesized azo-anthraquinone based dyes and calculated $\log$ P, molecular volume and aplanar shape that increased with alkyl chain length [18]. It was reported that good percent exhaustion and light fastness properties were exhibited. Burkinshaw and Jeong investigated the effect of ultrasound on color strength of six disperse dyes applied at $30-80^{\circ} \mathrm{C}$ [19]. It was reported that ultrasound didn't always result in good color strength. The intensification of chroma at $70^{\circ} \mathrm{C}$ in the presence of ultrasound was attributed to disaggregation of dyes or possibly to decrease in crystallinity of PLA. Dyeing at $80^{\circ} \mathrm{C}$ resulted in pale and dull shades, which was attributed to dispersion being broken.

The dyes exhibited good percent exhaustion on PLA. Choi et al. applied twelve phthalimide-derived azo dyes containing ester groups and reported that wash fastness in terms of staining and rubbing were extremely good while light fastness ratings were mostly in the range of 3 to 4 on Blue Wool Scale [20]. Ribba and Goyanes doped dyed PLA with $0.25 \%$ C.I. Disperse Orange 3 in the presence of $0.05 \%$ carbon nanotubes and reported $910 \%$ increase in strain at break and 100\% increase in toughness [21]. Tayfun and Dugan claimed superior dyeability of PLA modified with organoclay [22]. It was reported that organoclay reduced crystallinity; the tensile strength increased initially but decreased with the addition of 3 wt \% organoclay; however wash fastness of disperse was 
little affected. Baykuş et al. dyed N-phenylaminopropyl POSS (AP-POSS) nanoparticles with disperse dyes and reported the effectiveness of AP-POSS in enhancing the dyeability of PLA with disperse dyes of low uptake values [23]. In another study Baykuş et al. dyed octa(aminophenyl) polyhedral oligomeric silsesquioxane (OAP-POSS) modified PLA fibers with disperse dyes and reported that tensile strength and percent crystallinity decreased with increase in OAP-POSS while the dyeability was greatly improved for disperse dyes which otherwise had exhibited low uptakes [24].

\section{Vat dyes}

The vat dyes are universal in the sense that these dyes can be applied to almost all the fibers under suitable process conditions [25]. Sawada and Ueda dyed PLA fabrics with indigo dyes by the same method as was employed in the dyeing of cellulosic fibers and reported deep dyeing's with vat dyes, the maximum color yield being achieved at $373 \mathrm{~K}$, from the energy-saving viewpoint [26]. Since color strength decreased with increasing dyeing time from 1 to $5 \mathrm{~h}, 1 \mathrm{~h}$ of dyeing was chosen to be the optimum dyeing time. The maximum color yield was achieved at $5 \%$ o.w.f., further increase in dye concentration decreased $K / S(K-$ the coefficient of absorption, $S$ - the coefficient of scatter for the dyeing) values. Effects of auxiliaries $(\mathrm{NaOH}$, $\mathrm{Na}_{2} \mathrm{~S}_{2} \mathrm{O}_{4}$ ) on the dyeability of indigoids were found to be negative at high concentration. It is claimed that optimum concentrations of auxiliaries and dyes could be estimated using a simple linear regression. Burkinshaw et al. investigated the colorimetric properties of three indigoids on PLA at 2, 5, 8, 12 and 15\% o.m.f. (on-mass-of-fiber) at nine dyeing temperatures (60, 70, 80, 90, 98, 105, 110, 115 and $120^{\circ} \mathrm{C}$ ) and reported that color strength increased initially with increase in temperature up to $110^{\circ} \mathrm{C}$ and then decreased probably due to destruction/aggregation of dyes [27]. It was stated that the apparent decrease in color strength might also be due to hydrolysis of PLA. In another study, Burkinshaw et al. applied three indigoid and three anthraquinonoid vat dyes (5\% o.m.f.) on PLA knitted fabric at $60,80,98$ and $110^{\circ} \mathrm{C}$ and reported that for indigoids fastness to repeated-washings increased with increasing dyeing temperature [28].

\section{Basic dyes}

Basic dyes, the most brilliant colors, are characterized of having cationic chemical groups. Though mainly applied on acrylic and wool fibers, cationic-dyeable polyesters are available. Koo \& Jang dyed $\mathrm{UV} / \mathrm{O}_{3}$ irradiated PLA films with cationic dyes [29]. The irradiation resulted in the breakage of ester linkages in polymer backbone into hydroxy and carboxylic acid groups thus increasing hydrophilicity and generating potential dyesites. The enhanced dyeability of pretreated PLA films was attributed to electrostatic attraction between cationic chromogen and the anionic sites generated as a result of irradiation.

\section{Acid dyes}

Baykuş et al. spun PLA fibers using melt spinning with octaammonium polyhedral oligomeric silsesquioxane (OA-POSS) nanoparticles as additives [30]. The modified PLA was dyed with two acid dyes: one pre-metallized and the other one non-metallized. It was reported that percent crystallinity and tensile strength of modified PLA decreased with increase in OA-POSS while the dyeability was greatly improved.

\section{Natural dyes}

The natural dyes belong to a range of chemical classes. Sriumaroum et al. applied curcumin, a natural dye, on PLA and PET fabrics and reported good build up and a bathochromic shift on PLA as compared to PET [31]. Wu et al. investigated the effects of various dyeing factors on the dyeability of PLA with emodin, a natural dye, and reported a bright color with excellent fastness properties [32]. Ujjin and Jantip applied various natural dyes derived from marigold petals, rhubarb rhizomes, garcinia barks, turmeric rhizomes, sappan barks and catechu barks on PLA and reported that turmeric dye was the only one which gave high color yield on PLA [33]. Sriumaroum et al. dyed PET and PLA knitted fabrics by an exhaust technique with dyes viz., natural orange, natural red brown, turmeric, cassumunar and reported that dyes with poor aqueous solubility such as turmeric and cassumunar exhibited better exhaustion and color yield as compared to aqueous soluble natural orange and natural red brown dyes [34]. Wu et al. investigated the kinetics and thermodynamics of dyeing PLA fiber with curcumin through an exhaust technique [35]. It was reported that curcumin exhibited high exhaustion (90\%) and that the adsorption of curcumin on PLA followed Nernst isotherm, confirming the mechanism of dyeing PLA with curcumin was akin to disperse dyeing. Sidarkote et al. dyed PLA fabric with indigo by exhaust dyeing in the presence of $\mathrm{Na}_{2} \mathrm{~S}_{2} \mathrm{O}_{4} 5 \mathrm{~g} / \mathrm{dm}^{3}$ and $\mathrm{NaOH} 0.2 \mathrm{~g} / \mathrm{dm}^{3}$ sodium hydroxide [36]. The effect of dyeing variables viz., temperature, time and dye conc. were studied and it was reported that maximum color strength was achieved at $5 \%$ o.w.f. at $80^{\circ} \mathrm{C}$ for $60 \mathrm{~min}$.

\section{Pigments}

Pigments are the colorants that are immiscible in the application medium and are characterized of having little substantivity for textile fibers. Due to lack of substantivity, pigments are applied in the presence of binders. Upon curing, binders form coatings made up of crosslinked high molecular weight polymer networks in which pigment particles are embedded. The main advan- 
tages of pigment dyeing and printing are ease of application, single-bath dyeing of fiber blends, no after-treatments, good light fastness and acceptable crock fastness in light to medium shades. Karim et al. investigated the XPS analysis of thermally cured pigment prints on PLA [37]. It was concluded that decrease in bursting strength of printed fabric, cured at $150^{\circ} \mathrm{C}$, is due mainly to increase in carboxylate content. The SEM micrographs revealed that increase in crock fastness and stiffness might be attributed to cohesive binder films formed during curing. The optimum curing conditions were $140^{\circ} \mathrm{C}$ and $3 \mathrm{~min}$. Karim et al. printed PLA with pigments in the presence of UV-curable binders [38]. It was demonstrated that the inks with high acrylate content resulted in better overall color fastness properties, higher color strength and comparable color difference to thermally cured prints. It was claimed that physical and mechanical properties of PLA fabric were little affected during UV-curing.

\section{THERMODYNAMICS AND KINETICS OF DYEING}

The dyeing of textile fibers is a reversible process that can be studied in chemical thermodynamics. There are various stages involved in the disperse dyeing of polyester fibers and these include the dye-dispersion, dye-solubilization, dye transportation, adsorption, diffusion and migration. Each of these stages has its own importance and may be characterized separately. Thermodynamics of dyeing involves measuring adsorption isotherms that characterize the interaction between fiber and dye molecules. From the thermodynamics of dyeing, important parameters such as affinity, enthalpy and entropy of dyeings can be calculated.

$\mathrm{Xu}$ et al. studied the sorption thermodynamics and kinetics of C.I. Disperse Red 54 and C.I. Disperse Blue $165: 1$ on PLA fibers [39]. For Disperse Blue 165:1, the adsorption isotherms at 110,120 , and $130^{\circ} \mathrm{C}$ were of the Langmuir type while for Disperse Red 54 , at $110^{\circ} \mathrm{C}$ the adsorption followed Langmuir while at 120 and $130^{\circ} \mathrm{C}$ adsorption isotherms agreed well with Nernst type. The difference between the adsorption isotherms was explained by the dye solubility. The weak sorption affinities $\left(-\Delta \mu^{\circ}\right)$ of both dyes being $<1 \mathrm{kcal} / \mathrm{mol}$ were attributed to weak dye-fiber interactions and strong dye-solvent interaction. Enthalpy changes $\left(\Delta H^{\circ}\right)$ and entropy changes $\left(\Delta S^{\circ}\right)$ showed that the sorption process was enthalpy-driven. Sorption kinetics suggested a pseudo second-order kinetic model for disperse dyes on PLA fibers. Raising dyeing temperature decreased the halftime, increased dyeing rate constant and diffusion coefficient. Temperature dependence of diffusion coefficients was well reproduced using molecular collision based diffusion model. The activation energies of diffusion had been determined and rationalized using molecular volume of dyes. The result might provide predictive tools for the investigation of dye compatibilities and migration modelling of PLA packaging materials. Xu et al. devel- oped two predictive models for the adsorption affinities and diffusion coefficients of disperse dyes on PLA matrix in non-aqueous medium, the only parameters being required for both the models were temperature and the solvent accessible surface area (ASA) of dye molecules [40]. The developed models were validated using two azo and two anthraquinone dyes. Reliable models for adsorption affinity and diffusion coefficient enabled computation based selection for improved dye uptake and better dye compatibility on PLA fibers. It was emphasized that surface area based predictive models might not hold true for the systems containing dominant interactions other than van der Waals forces, the quantitative structureproperty relationships in such systems requiring further investigation. Kinetics of dyeing characterizes the reaction rates i.e. how fast/slow dyeing takes place. From the kinetic study of dyeings, important parameters such as diffusion coefficients, activation energy, reaction velocity and time of half-dyeing may be calculated. Fu et al. determined the affinity and diffusion coefficient of three disperse dyes on PLA and reported that higher the values of affinity and diffusion, higher would be dyeing rate [41].

\section{DYEING TECHNOLOGIES}

Most of the textile fibers are processed at ambient atmospheric pressure; however polyester fibers are typically dyed at elevated temperature under pressure. On industrial scale, PET is dyed at $130^{\circ} \mathrm{C}, \mathrm{pH} 4.0-4.5$ for 45-90 minutes [42]. Dyeing PET at high temperature allows efficient exhaustion of the dye and the ability to achieve level and deep shades. However unlike PET, the recommended dyeing conditions for PLA are $110^{\circ} \mathrm{C}, \mathrm{pH}$ 4.5-5.0 and 30 minutes $[6,43]$. The lower dyeing temperature of PLA as compared to PET is due to the inferior hydrolytic stability of PLA particularly at high temperature and longer processing time [44, 45]. It was recommended that holding the dyeing temperature at $90-95^{\circ} \mathrm{C}$ for $5 \mathrm{~min}$ might be beneficial in obtaining shades of good levelness with dyes of poor levelling properties. Finally the dyebath should be dropped below $50^{\circ} \mathrm{C}$ to avoid fabric creases [46]. In another study, Yang and Huda advised that a gradual decrease in dyebath temperature might enhance dye exhaustion on PLA as dyeing was an exothermic process $[47,48]$. Nakamura et al. and Nakamura stressed the importance of liquor to material ratio that affected dye uptake, for light and medium shade depths $[49,50]$. It was claimed that in heavy shade depths, the dyeing temperature played the most significant role with respect to the maximum equilibrium dye uptake. It is important to realize that long liquor ratios cost high in terms of electricity, heating and also inflict excessively on waste treatment plants.

Carrier dyeing is an exhaust technique wherein polyester textiles are imparted color in a dyebath containing suitable organic aromatic compounds. These compounds which have low solubility in water and a similar chemical 
and physical nature to the fiber are called carriers. Due to low aqueous solubility, the industrially available carriers are oil in water $(\mathrm{O} / \mathrm{W})$ emulsions of organic chemicals having milky appearance. There are different theories about the mode of action of carriers. Carriers may lower glass transition temperature $\left(T_{o}\right)$ so that dyeing can take place at low temperature. Another point of view is that since carriers are organic compounds and so are the polyester fibers, e.g. PET and PLA, the carriers swell the fibers resulting in faster penetration of disperse dyes into the fibers. Carriers may also interact with disperse dyes thereby enhancing their hydrophobicity and hence better exhaustion on the hydrophobic fibers [51]. In addition to enhancing exhaustion properties, carriers also improve the dye migration properties within the fibers. Baig dyed PLA with disperse dyes in the presence of a range of commercially available carriers and reported different levels of success in achieving good color strength [25]. Kinashi et al. applied a photochromic dye to PLA in aqueous and solvent mediums [52]. In aqueous medium, the dyeing was carried out in the presence and absence of carriers such as o-phenylphenol (PP) and benzyl alcohol at $40^{\circ} \mathrm{C}$ for $24 \mathrm{hrs}$. It was reported that optimal dye transfer $(K / S$ : 21.0) took place in the presence of PP.

Non-aqueous media such as supercritical carbon dioxide $\left(\mathrm{sc}-\mathrm{CO}_{2}\right)$ is being investigated as an alternative to aqueous based dyeing systems. Bach et.al., dyed PLA with C.I. Disperse Red 167:1 (4\% o.m.f.) and C.I. Disperse Blue 79 in sc- $\mathrm{CO}_{2}$ at $28 \mathrm{MPa}$ for $1 \mathrm{~h}$ at temperatures in the range of $50-95^{\circ} \mathrm{C}$ [53]. It was reported that though maximum dye uptake for red dye was obtained at $90^{\circ} \mathrm{C}$, even at $50^{\circ} \mathrm{C}$ the fibers were completely dyed. Dyeing above $90^{\circ} \mathrm{C}$ led to hardening and crinkling of the knitted fabric. Dyeing of PLA in sc- $\mathrm{CO}_{2}$ medium with C.I. Disperse Blue 79 was also carried out and it was shown that the breaking strength loss of PLA dyed in $\mathrm{sc}-\mathrm{CO}_{2}$ at $120^{\circ} \mathrm{C}$ for 60 minutes was only $9.2 \%$ while there was a loss of $44.7 \%$ at the same process conditions in aqueous medium [54]. PET has been dyed with disperse dyes in the presence of suitable organic solvents as well, though there is a little work published on the solvent dyeing of PLA fibers. In a recent study, Xu et al. dyed PLA with disperse dyes in non-aqueous medium such as liquid paraffin and claimed high quality dyeings being obtained [55]. The color fastness of solvent and aqueously dyed fabrics was found to be comparable. In a recent study, Xu et al. extended the concept of using liquid paraffins, as dyeing medium, to other polyester fibers as well [56].

\section{COLORIMETRIC PROPERTIES}

The most important properties of dyes on textiles during dyeing are their substantivity, exhaustion, buildup, strike, levelling and fastness properties. The dye buildup gives information about their tinctorial strength; the dyes exhibiting high color strengths at low shade depths having stronger tinctorial strengths. These dyes are economi- cal from cost point of view and intuitively attract lower transportation cost as well. Exhaustion is another important dye property, dyes with higher exhaustion profile always being preferred due to lesser amount of colorants being discarded into waste effluent. The level of exhaustion of dyes depends on the shade depth applied as well. Most of the dyes exhaust well at low shade depths, but in deep shades exhaustion decreases owing to the limitations imposed by the maximum amount of dye that fibers can absorb; the fibers becoming saturated at a particular shade depth. Further increase in dye concentration in the dyebath does not lead to any appreciable changes in color strength. The importance of color strength and color coordinates cannot be underestimated in industrial color matching. Choi and Seo and Choi et al. stated that the yellow and blue disperse dyes were greener whereas orange/red dyes were yellower in hue on PLA than on PET [57, 58]. PLA dyeings showed greater lightness $\left(L^{*}\right)$, chroma $\left(C^{*}\right)$ and hue angle $\left(h^{\circ}\right)$ values as compared to PET dyeings. It was stated that greater values of chroma are indicative of brighter shades being produced on PLA than on PET for a particular dye. It was difficult to achieve dark shade such as navy and black on PLA due to lower exhaustion levels. However, deep black shades were obtained on PLA fibers containing high percentage of D-isomer while a more brownish black was achieved on low-D PLA fibers because of the lower exhaustion of the blue component of the mixture [59]. Fattahi et al. dyed PLA pre-treated with $\mathrm{UV} / \mathrm{O}_{3}$ and concluded that color depth of disperse dyes increased on PET and PLA; the increase in depth of dyeing was claimed to be due to surface roughening of the fibers during irradiations [60].

\section{Buildup properties}

The buildup of disperse dyes varies among different chemical classes of dyes. Mathematically, the buildup may be defined as the rate change of color strength as a function of shade depth. Baig applied a range of disperse dyes on PLA knitted fabric at 60 to $130^{\circ} \mathrm{C}$ and reported color strength $(K / S)$ in the range of 5-23 among disperse dyes [1]. It was stated that except C.I. Disperse Red 167:1, all others reported dyes reached to the maximum $K / S$ at $110^{\circ} \mathrm{C}$ which is the recommended dyeing temperature for PLA fibers [6]. Another corollary of the above research was that existing disperse dyes might be classified for PLA based on kinetic properties.

\section{Exhaustion properties}

The exhaustion, usually expressed as $\%$, is a measure of the relative amount of dye absorbed by the fibers. Mathematically, it is the difference in absorption of dye before and after dyeing expressed as a percentage. Since the commercially available disperse dyes have been designed for PET fibers, for PLA the buildup and exhaustion varies. It was stated that medium-energy disperse 
dyes were the most suitable for dyeing PLA [61]. Lunt and Bone, applied nine disperse to PLA at $110^{\circ} \mathrm{C}$ for $60 \mathrm{~min}$ utes and all the nine disperse dyes had $80 \%$ exhaustion levels [62]. Five of the nine dyes exhibited very similar performances in terms of percentage exhaustion on both PLA and PET substrates, the degrees of dye exhaustion being generally equal to or lower than that on PET. It was known that the low saturation balance of PLA fibers led to a lower dye uptake and poor buildup properties as compared to PET [49]. Yang and Huda applied ten disperse dyes on PET and PLA and it was observed that all the dyes exhibited high exhaustion on PET compared to PLA [47]. C.I. Disperse Red 60 exhibited high diffusivity and low saturation dye uptake on PLA. It was reported that the rate of dye diffusion was much higher in PLA than that of PET. According to a research undertaken on the effect of disperse dye class on exhaustion, it was found that medium-energy dyes produced high levels of exhaustion on PLA, whereas high- and low-energy dyes gave variable and low exhaustion, respectively [6]. Karst \& Yang 2005, stated that exhaustion of disperse dyes might be correlated with the concept of solubility parameter [11]. The dyes having solubility parameter close to that of PLA might exhibit good exhaustion properties. Those dyes that didn't have solubility parameter close to that of PLA might be substituted with suitable chemical groups to pull their solubility parameter close to that of PLA. Choi and Seo applied twenty disperse dyes of differing energies on PLA and PET fabrics and reported a wide range of exhaustion (12-88\% at $4 \%$ o.w.f.) among dyes [57]. Nine dyes that exhausted above $70 \%$ were screened for further comparison of shade and fastness properties between PLA and PET. In another study Choi et al. applied twenty two disperse dyes that consisted of high-light-fast dyes for polyester and amongst two ranges of dyes for diacetate [58]. It was reported that only eight dyes exhibited exhaustion above $60 \%$ when applied at $4 \%$ o.w.f., $110^{\circ} \mathrm{C}$ for $40 \mathrm{~min}$. It was also reported by the same authors that though C.I. Disperse Blue 374 and C.I. Disperse Blue 284 exhibited exhaustion levels of 60.6 and $43.8 \%$, respectively at $2 \%$ o.w.f., a $60: 40$ mixture of Blue 374 and Blue 284 formed a synergistic mixture as the exhaustion increased up to $87 \%$ which was higher than each of the dyes alone. Liang et al. synthesized a range of hydrophobic anthraquinone disperse dyes containing alkyl substituents of varying lengths and applied on PLA $[9,10]$. The exhaustion values of these dyes as compared to C.I. Disperse Blue 3, C.I. Disperse Blue 56 and C.I. Disperse Blue 73 were up to 85 and $50 \%$, respectively. Liang et.al., prepared azo-anthraquinone disperse dyes and reported that the optimum dyeing conditions for PLA were $90^{\circ} \mathrm{C}, \mathrm{pH} 5.0$ and $60 \mathrm{~min}$ at which maximum exhaustion values were achieved (ca. 65\%), however, except one the other two dyes exhibited up to $80 \%$ exhaustion on PET [13]. Choi et al. dyed PLA with 18 carbocyclic azo dyes bearing a hydrolysable $\mathrm{N}$-alkylphthalimide, substituted with various alkyl sub- stituents viz., $n$-butyl, sec-butyl, or iso-propyl, while the adjoining phenyl ring bore-CN and -Br groups [14]. It was claimed that there existed a broad correlation between dye exhaustion onto PLA and PET fibers. No relationship was found between percentage exhaustion and partition coefficients $(\log \mathrm{P}) /$ solubility parameter values. As was found to be the case with PET, the wash fastness of dyes on PLA tended to be highest when their diazo ring was substituted with electron acceptors. Sriumarom et al. applied curcumin, a natural dye, on PLA and PET fabrics and reported good build up and a bathochromic shift on PLA [31]. Wu et al. investigated the effects of various dyeing factors on the dyeability of PLA with emodin, a natural dye, and reported a bright color with excellent fastness properties [32]. Burkinshaw and Jeong carried out ultrasound-assisted disperse dyeing of PLA [63]. It was reported that ultrasound enhanced color strength of three of the six dyes, the increase in color strength being attributed to the disaggregation of dyes and decrease in crystallinity of fiber. However, dyeing at $80^{\circ} \mathrm{C}$, resulted in the pale and dull shades for five dyes due to the dye dispersion being broken. In another study the same authors investigated the effect of ultrasound on fastness properties of disperse dyed PLA knitted fabric. It was concluded that ultrasound imparted more color strength to dyeings before and after reduction clearing for five of the six dyes. The observed decrease in rubbing fastness was attributed to the initial greater color strength of ultrasonicassisted disperse dyeings [63]. Lihua et al. measured the exhaustion of five yellow azo-anthraquinone disperse dyes on PLA and reported good exhaustion percentage [18]. It was reported that the alkyl substituents had little influence on dye color. Choi et al. prepared twelve phthalimide-derived azo dyes containing ester groups and reported exhaustion values as low as $33.5 \%$ to as high as $95.2 \%$ [20]. No correlation was found between exhaustion (\%) and calculated solubility parameters presumably the influence of dye structure being masked the heavy depth applied ( $4 \%$ o.w.f.), dispersion stability, particle size and crystal morphology.

\section{Spectroscopic properties}

The polymer environment affects the light absorption properties of dyes. The brightness of PET and PLA can be explained in terms of Fresnel's reflection. Since surface reflection decreases with decrease in refractive index, it is logical that PLA dyeings will look brighter than PET when dyed to the concentration, i.e. same number of dye molecules per unit volume of fiber. It was stated that deep shades could be more easily produced on PLA than PET due to lower refractive index (1.35-1.45) of the former [61, 64]. Some workers claimed that brighter shades were produced on PLA [64].

An incident light will follow the longest path, if passing through the same medium. Since the refractive index of PET is higher than PLA, the path length for the latter 
will be longer. Since the absorption of light is directly related to the path length (l), PLA fabrics will exhibit deep-dyeings if PLA and PET are dyed with a certain dye to the same shade depth in terms of the number of molecules per unit volume of fiber. It was claimed that color strength on PLA would be higher than on PET if both the fibers had the same amount of dye in the bulk [50,64]. Avinc showed that a lower quantity of disperse dyes was required (ca. $25 \%$ less) to produce a color strength $(K / S)$ of 20 on PLA than on PET [65]. It was claimed that the lower reflectance of PLA compared to PET resulted in less dye being needed on the former to achieve the similar color strength.

A comparison of the color yield obtained on PLA fiber as compared with that on PET showed that most of the azo dyes appeared stronger on PLA, which was in agreement with their solution appearance in ethyl acetate compared with methyl benzoate, chosen to simulate the polar properties of the two fibers [66]. Nakamura applied C.I. Disperse Red 60 at $100^{\circ} \mathrm{C}$ to PET and PLA and reported that the lower refractive index of PLA allowed higher color strength to be produced [51]. The reflection spectra of the same dye applied on PLA and PET fibers might exhibit shifts in the wavelengths of maximum absorption $\left(\lambda_{\text {mor }}\right)$, the maximum shift being noted was $20 \mathrm{~nm}$. The polymer environment affected the light absorption properties of dyes [1]. Since PET and PLA are aromaticaliphatic and aliphatic polyesters, it is likely that the interactions between dye and fiber will differ. Nakamura applied C.I. Disperse Red 60 at $100^{\circ} \mathrm{C}$ to PET and PLA and showed that the wavelength of maximum absorption $\left(\lambda_{\max }\right)$ was at a shorter wavelength for PLA [50]. Curcumin, a natural dye, was applied on PLA and PET fabrics and a bathochromic shift on PLA was reported [34]. Cui et al. dissolved phenylazopyrazolone-containing acylamide dyes in acetone and dimethylformamide (DMF) solvents to record spectral data [17]. It was reported that substituents had little effect on $\lambda_{\max }$ when dissolved in the same solvent, whereas changing the solvent does. Change in solvent from acetone to DMF resulted in bathochromic shift $\left(\Delta \lambda_{\max }: 8\right.$ to $\left.13 \mathrm{~nm}\right)$. The bathochromic shift was explained in terms of increase in solvent polarity from 20.56 (acetone) to 36.71 (DMF). The superior stabilization of the dye's excited electronic state, when dissolved in $\mathrm{DMF}$, led to a lower energy gap between the ground and excited states of the dye molecules and resulted in a bathochromic shift [67].

The reflection/transmission spectra of dyes are an excellent representation of filters that attenuate selected wavelengths of light while allowing others to pass through unaffected. The reflection spectrum of C.I. Disperse Red 167:1 showed that this particular dye allowed mainly the long wavelengths of light along with some of the shortwavelengths. Therefore the dye looked bluish red. The integration of area under the curve weighted with suitable color matching functions yields chromaticity coordinates whose transformation generates $L^{*} a^{*} b^{*}$ values. The
$L^{*}$ gives information about the lightness while other two terms provide information about the tone of a dye. The color coordinates have industrial significance in that the shades have to be matched such that there is little perception of the color difference. Since the reflection spectra of PLA was slightly shifted to the left, due changes would have to be done to produce the same shade on PLA as on PET textiles.

\section{FASTNESS PROPERTIES}

Color fastness is another important quality characteristic of dyeings. The fastness properties such as wash, crock and light of disperse dyes have been investigated by many researchers. The general trend is that color fastness of disperse dyes tend to be lower on PLA than on PET, at similar shade depths. The following sections discuss selected fastness properties of dyed PLA textiles.

\section{Wet fastness}

It has been claimed that most of the disperse dyes on PLA fiber would have wash fastness acceptable for apparel applications; that disperse dyes on PLA exhibited good resistance to fading by nitrogen gas fumes and that PLA fabrics exposed to outdoor light, having UV content, faded slightly more than those exposed to indoor exposure due to the difference in photo-energy distributions of the light sources. PLA is more transparent to UV radiation in the 370-240 $\mathrm{nm}$ range than PET, resulting in poor light fastness of disperse dyes on PLA due possibly to the destruction of dye chromophore, especially for blue dyes [49]. It was reported that the effect of L- and D-isomers would have negligible effect on wash fastness as the glass transition temperature depended little on the contents of L-/D-isomers [59]. Bach et al. reported that wash and rub fastness of PLA fiber dyed in sc- $\mathrm{CO}_{2}$ medium was good to very good even without any after-clearing being carried out in cold sc- $\mathrm{CO}_{2}$ [53]. Choi and Seo reported that when comparing the wet fastness of disperse dyes ( $4.0 \%$ o.w.f.) on PLA and PET, ratings were either similar or slightly worse on the former [57]. It was also mentioned that the photo-stabilities of nitro-diphenylamine, monoazo, and anthraquinone chromophores on PLA were very similar to those observed on PET except C.I. Disperse Blue 284. Choi et al. reported that the wash fastness of eight, out of twenty, disperse dyes exhibiting good exhaustion on PLA were either the same or 1 to 2 points less than on PET [58]. Liang et al. reported that the substitution of amino groups had little effect on wash fastness of AQ dyes [10]. Choi et al. dyed PLA with 18 carbocyclic azo dyes bearing a hydrolysable phthalimide moiety substituted with various alkyl substituents viz., $n$-butyl, secbutyl, or iso-propyl, while the adjoining phenyl ring bore $-\mathrm{CN}$ and -Br groups [14]. It was claimed that wash fastness were relatively good compared to that of some conventional disperse dyes applied to PLA. As was found to 
be the case with PET, the wash fastness of dyes on PLA tended to be highest when their diazo ring was substituted with electron acceptors. Lihua et al. synthesized five yellow azo-anthraquinone disperse dyes containing different alkyl substituents on the phenyl alkyl-sulfonamide [18]. It was reported that for optimal wash fastness the chain length shouldn't exceed C-6. Burkinshaw and Jeong applied six disperse dyes on PLA in the presence of ultrasound and reported decrease in wet and dry rubbing as well as to two/three out of five wash cycles [63]. It was suggested that decrease in fastness was due to enhanced color strength imparted due to ultrasound during dyeing. Choi et al. applied twelve phthalimidederived azo dyes containing ester groups and reported that wash fastness in terms of staining and rubbing were extremely good [20]. Avinc et al. reported that decrease in wet fastness of selected disperse dyes on PLA as compared to PET occurred as a result of thermal migration during drying at $110^{\circ} \mathrm{C}$ [68].

\section{Light fastness}

Mogi et al. studied the light fastness of twelve azo and AQ disperse dyes (1\% o.w.f.) on PLA fabrics, exposed to carbon arc lamp, and reported that discoloration increased with increase in exposure time [69, 70]. The azo disperse dyes containing cyanoethyl or acetoxyethyl substituents exhibited high light fastness. While cyano or chloro groups had synergistic effect on light fastness, the methyl group showed a negative effect. Deep-dyed PLA fabric tended to exhibit higher light fastness than a paler color one. PLA fabrics dyed with thirteen anthraquinone based dyes was subjected to the above conditions and reported that though PLA fabric dyed with C.I. Disperse Red 127 and C.I. Disperse Violet 27 dyes exhibited the highest light fastness grades, the fastness rating decreased when PLA was dyed with their mixture thus these dyes had antagonistic effect on each other. The selection of proper dyes and the use of suitable UV absorbers could be a solution obtaining higher light fastness results [49]. Yang and Huda 2003 reported that akin to wash and rub fastness, the light fastness of disperse dyes was lower on PLA than on PET fabrics [47]. Mogi et al. studied the effects of benzotriazole class of UV absorbers on the light fastness of PLA fabrics dyed with C.I. Disperse Orange 25 and C.I. Disperse Orange 44 azo disperse dyes and reported an increase from 3.0 to 3.8 and 1.1 to 2.9, respectively, assessed by instrumental method [71]. On the other hand, the same UV absorber had detrimental effect on AQ disperse dyes such as C.I. Disperse Red 60 and C.I. Disperse Red 127. Choi and Seo 2006 reported that the photo-stabilities of nitro-diphenylamine, monoazo, and anthraquinone chromophores on PLA were very similar to those observed on PET except C.I. Disperse Blue 284 [57]. However, the color difference $\left(\Delta E^{\prime \prime}\right)$ upon testing light fastness were greater in the case of the PLA dyeings as compared with PET. Choi et al. reported that light fastness of six high-light-fast disperse dyes was 0.5 or 1 grade (Blue Wool Scale) less on PLA than on PET [58]. Dorospers G/YEL KBGL was recommended as a good choice for dyeing PLA to meet the super light fastness requirement. Liang et al. claimed that the substitution of halogens into the anthraquinone chromogen could be improved the light fastness on PLA [9]. Liang et al. also reported that the light fastness of $A Q$ dyes containing aromatic-amino or cyclo-fatty amino groups was higher than with fatty-amino groups [10]. Lihua et al. synthesized five yellow azo-anthraquinone disperse dyes containing different alkyl substituents on the phenyl alkylsulfonamide [18]. It was reported that alky chain length had little effect on light fastness.

\section{Migration properties}

Dry heat, particularly in the presence of finishes such as softeners, may cause migration of disperse dyes to the surface of PLA fibers. The thermally agitated non-ionic disperse dyes in the presence of softeners which themselves are non-ionic chemicals may aggravate the migration behavior of disperse dyes. The migration of dyes to the surface may adversely affect the fastness properties of dyeings. Nakamura et al. reported that heat-setting treatment decreased wet fastness of dyed PLA fabric [49]. Phillips et al. reported that, comparing with PET, the wet fastness of dyed PLA was generally lower after heat-treatment due possibly to the migration of disperse dyes to the surface of substrates [43]. Avinc et al. applied softeners on PLA and PET dyed with the same dyes and reported no correlation between the hydrophobicity of dyes and softeners [72]. Choi et al. applied twelve phthalimide-derived azo dyes containing ester groups and reported that light fastness ratings were mostly in the range of 3 to 4 [20].

\section{AFTER TREATMENTS}

It is important to realize that exhaustion is never complete, particularly in deep shades. Since adsorption is a constitutive stage in the dyeing of textile fibers, at the end of dyeing some of the dye molecules do remain occluded in the surface of polyester fibers. Being insoluble in aqueous medium, these disperse dye particles cannot be cleared-off easily by simple washing treatments. But since disperse dyes do have limited aqueous solubility, these dye molecules will continue to bleed into laundering liquor during washing thus staining and impairing visual aesthetics of the white and pale colored garments. Another issue closely attached with polyester dyeing is the deposition of low molecular weight polyesters on the surface of fibers. Due to being low molecular weight species, these kinetically-triggered oligomers diffuse out from the bulk of the fibers and being insoluble in aqueous medium deposit on the surface of textiles. These oligomers, if not removed, deposit in the yarn-guides and build on various machine parts as white substance thus 
affecting surface properties of yarns. These white precipitous substances are also a source of nuisance and badly affect productivity during yarn manufacturing. Over the time, oligomers may also buildup in the dyeing machines particularly on rough surfaces. If the machines are not cleansed properly, these oligomers may provide nucleation sites for disperse dyes to grow thus destabilizing the dye dispersion. Though not affecting dyeing properties, the performance of finishes are badly affected if the dispersing agents are not removed from the surface of textiles after dyeing. It is important, therefore, to remove surface deposited dye, oligomers and auxiliaries so that quality dyeings are obtained [51].

Hydrolysis is a chemical reaction, usually catalyzed in the acidic or alkaline $\mathrm{pH}$, which involves the addition of water molecules into a chemical compound. If the disperse dyes have hydrolysable groups such as esters, cyanides, etc. the hydrolysis can transform these polar groups into water-solubilising groups usually carboxylic acid and hydroxyl functional groups. Since hydrolysis is usually carried out in the alkaline $\mathrm{pH}$, the carboxylic acid groups are dissociated into carboxylates turning disperse dyes into water-soluble compounds. Park et al. dyed PLA fabric using temporarily solubilized azopyridone based disperse dyes [73]. It was claimed that the wash and light fastness results obtained from reduction-clear (RC) and alkali-clear (AC) methods were comparable.

Reduction is a chemical reaction that involves the addition of electrons into a chemical compound. Reduction clearing i.e. the removal of disperse dyes using reducing agents, is the most widely practiced technique in the textile industry to clear surface-deposited dye particles. Upon reductive fission, the disperse dyes may be converted into smaller fragments that are very easily washedoff. The most widely used inorganic reducing agent is sodium dithionite $\left(\mathrm{Na}_{2} \mathrm{~S}_{2} \mathrm{O}_{4}\right)$ while the organics include hydroxyacetone, hydroxymethylsufhinate, formamidine sulfonic acid/thiourea dioxide (FAS/TUDO) and iron salts. Avinc examined the effect of acid and alkaline RC of PLA dyed with disperse dyes and reported that neither of the methods adversely affected the polymers molecular weight and fabric tensile properties [65]. Avinc et al. studied the effect of various RC conditions on dyed PLA and concluded that the preferred conditions, where least color loss and good wash fastness were obtained, were $\mathrm{Na}_{2} \mathrm{~S}_{2} \mathrm{O}_{4} 2 \mathrm{~g} / \mathrm{dm}^{3}, \mathrm{Na}_{2} \mathrm{CO}_{3} 2 \mathrm{~g} / \mathrm{dm}^{3}$ for 15 minutes at $60^{\circ} \mathrm{C}$ [74]. Bach et al. reduction cleared dyed PLA in supercritical carbon dioxide and reported a decrease in color depth and non-uniform shade [53]. Burkinshaw et al. studied the ultrasonic-assisted reduction-clear (RC) washing of dyed PLA and reported that the presence of ECE (ECE is the European Colorfastness Establishment) detergent assisted in the removal of surface deposited dye whereas water alone even in the presence of ultrasound didn't have much effect on color strength [75-77]. Avinc studied the effect of air, in the RC bath, on the washing fastness of disperse dyed PLA and reported that the lower air content, higher amounts of $\mathrm{Na}_{2} \mathrm{~S}_{2} \mathrm{O}_{4}$ and long liquors led to better wash fastness of disperse dyes [78]. Avinc RC washed PLA knitted fabric with sodium dithionite under acidic conditions and reported that the improvement in the wash fastness was lower in acidic than in the alkaline medium [79].

Avinc et al. oxidatively cleared disperse dyed (C.I. Disperse Red 167:1 \& Blue 148 each at 1 and 2\% o.w.f.) PLA knitted fabrics using ozone in neutral distilled water at room temperature [80]. It was reported that none of the ozonation processes resulted in high wash fastness and that when ozonated for long dwell times, it resulted in high color differences. As an addition, warm soaping steps of 1 and 3 min followed ozonation carried out at $200 \mathrm{~cm}^{3} / \mathrm{min}_{3}$ gas flow rate. It was reported that though soaping of $1 \mathrm{~min}$ after ozonation improved wash fastness to acceptable levels, the results of conventional RC treatment were still better. Eren et al. blew $\mathrm{O}_{3}$ on wet disperse dyed polyester and reported wash fastness comparable to RC method with little loss of mechanical strength and added advantage of low water consumption [81]. Eren also reported that clearing with $\mathrm{O}_{3}$ produced better wash fastness than conventional $\mathrm{RC}$ treatment without causing significant changes in color [82]. Oxidative clearing (OC) also led to a lower value of COD (the Chemical Oxygen Demand) of the effluent. In another study Eren treated disperse dyed polyester with gaseous $\mathrm{O}_{3}$ for 1-15 min at ambient conditions [83]. When compared with RC treated samples, there was not much difference in lightness except of a high-energy blue dye which belonged to azo class. It was concluded that $\mathrm{O}_{3}$ improved wash fastness but at the expense of change in hue. Ozone treatment for $>1$ min also led to loss in mechanical properties. The OC was particularly valuable when the dyeing of PC blends was carried out in a neutral bath as the dyed fabric could be subjected to $\mathrm{RC}$ due to degradation of reactive dyes [84]. Gomes et al. compared the oxidative and reductive clearing techniques and concluded that $\mathrm{OC}$ is environment friendly [85]. Since AQ dyes are prone to oxidation, therefore, there always remain some dyes residues which may be removed by an oxidative treatment. These residues, on PET, may be removed in a mildly alkaline bath containing $\mathrm{NaClO} 3 \mathrm{~g} / \mathrm{dm}^{3}$ available $\mathrm{Cl}_{2}$ at $50-60^{\circ} \mathrm{C}$. However, chlorine bleaches do require an anti-chlor treatment to remove traces of chlorine which otherwise may cause yellowing and generate fishing odors due to the formation of chloramines. Other possible oxidizing agents may be peracetic acid or activated hydrogen peroxide systems that work at low temperature.

\section{FUTURE TRENDS}

Since textile industry consumes huge amounts of water, the disposal of wastewater with high biodegradability index COD/BOD (BOD - Biochemical Oxygen Demand) is a concern worldwide. Alternative dyeing mediums such as super-critical carbon dioxide and special wax formulations have been reported in the litera- 
ture. The main issues with sc- $\mathrm{CO}_{2}$ technology are high cost; lack of skilled workforce and operating machine at high pressure. Eco-friendly chemicals such as hydrogen peroxide and activated oxidation systems viz., sodiumperborate/tetra-acetylethylenediamine (TAED), sodiumperborate/nonanyl-oxybenznesulfonate (NOBS) and quaternary compounds based systems may be investigated as alternative clearing-off treatments.

Dyeing and finishing of fiber-blends is of special interest from industrial viewpoint. Since the hydrolytic and thermal stability of PLA is poor as compared to PET, alternative processing routes or new unit operations have to be designed or developed, respectively, that work at mild process conditions. The dyeing of PLA-cotton and PLA-wool blends is challenging because the poor stability of PLA imposes a number of restrictions in choosing the right dyeing techniques. One solution is to dye these blends with pigments in the presence of binders that either cure at relatively low temperatures or can be cross-linked using UV radiations. Doped dyed PLA can be mixed with other dope-dyed manmade fibers to achieve aesthetic and performance properties in blends.

Biotechnology is likely to play an important role in the surface modification of PLA textiles. The use of enzymes in the after-treatments of disperse dyeings may be of special interest. It has been reported that cutinases can hydrolyze the cyclic oligomers of polyester. Aleem assessed two enzymes i.e. a hydrolase and an oxidoreductase, as an alternative to RC method, but didn't get satisfactory results [86].

Electrochemistry may be taken advantage of in a number of areas. In situ preparation and utilization of chemicals in the same bath for textile applications is an excellent idea. The denim industry is already using electrochemical systems in washings. Aleem employed electrochemical method was also investigated using $\mathrm{Fe}^{3+}-$ triethanolamine (TEA) complex to reduce $0.1 \mathrm{~g} / \mathrm{dm}^{3}$ dispersion of C.I. Disperse Red 73 but no satisfactory results were reported [86].

Use of advanced technologies such as corona discharge and plasma treatments has been reported in literature. As a proof of concept, polyester fabric padded only with a disperse dye was plasma-treated using oxygen, air, water vapor and hydrogen as feeding gases. It was reported that hydrogen gas afforded acceptable wash fastness results. Plasma treatment may be used to improve wicking, charge dissipation and improving adhesion of coatings on PLA. Computational science can solve a number of mysteries. Molecular modelling may be employed to investigate dye-fiber interactions thus helping synthesize disperse dyes tailored for PLA fibers. Artificial Neural Networks (ANN) and Artificial Neural Networks - Fuzzy Inference System (ANN-FIS) are of special interest in modelling the color match systems. The recipes developed for PET may be used to predict recipes for PLA using artificial intelligence applications. The mechanical and colorimetric properties may be mod- elled using ANN and related techniques to predict the optimum process conditions for PLA.

\section{CONCLUSION}

PLA fibers have the attractive features of biodegradability and sustainability. One of the major milestones in the success of PLA is that improved and more efficient polymerization methods have been developed that have made it possible to synthesize high molecular weight PLA polymers tailored for various applications. Since existing disperse dyes have been developed keeping in view the chemistry and structure of PET, the industrially available disperse dyes exhibit variable levels of substantivity, exhaustion and fastness properties on PLA. New disperse dyes with different substituents have shown good exhaustion on PLA; and in some cases very good wash and light fastness properties have also been reported. Molecular modelling techniques have increasingly been taken advantage of in understanding the dye-fiber interactions and have proved to be a useful tool in designing new disperse dyes with enhanced dyeing properties. PLA has been dyed with various natural and synthetic dyes in aqueous medium. It has been argued that at the same concentration of dye in the fibers, PLA dyeings look not only deeper but brighter as well when comparing with corresponding PET dyeings. Though most of the work has been on aqueous-based dyeing systems, non-aqueous dyeing of PLA has also been investigated and these include the $\mathrm{sc}-\mathrm{CO}_{2}$ and more recent liquid paraffin as a medium of dyeing. It has been realized that the existing processing technologies and protocols have been designed for PET and therefore they require modifications as the thermal and hydrolytic stability of PLA is far less than that of PET fiber.

\section{REFERENCES}

[1] Baig G.A.: Ph.D Thesis, University of Manchester, UK 2012.

[2] Baig G.A., Carr C.M.: Polish Journal of Chemical Technology 2014, 16 (3), 45. http://dx.doi.org/10.2478/pjct-2014-0049

[3] Phillips D., Suesat J., Wilding M. et al.: Coloration Technology 2003, 119, 128. https://doi.org/10.1111/j.1478-4408.2003.tb00162.x

[4] Phillips D., Suesat J., Wilding M. et al:: Coloration Technology 2004, 120, 41. https://doi.org/10.1111/j.1478-4408.2004.tb00205.x

[5] Phillips D., Suesat J., Wilding M. et al.: Coloration Technology 2004, 120, 35. https://doi.org/10.1111/j.1478-4408.2004.tb00204.x

[6] DyStar, Textilfarben GmbH \& Co. Deutschland KG, 'Ingeo ${ }^{\mathrm{TM}}$ Fiber Coloration Pack', DyStar plc 2004.

[7] Avinc O., Khoddami A.: Fibre Chemistry 2010, 42 (1), 68.

[8] Hussain T., Tausif M., Ashraf M.: Journal of Cleaner Production 2015, 108, 476.

http://dx.doi.org/10.1016/j.jclepro.2015.05.126 
[9] He L., Zhang S.F., Bing T.T. et al.: Chinese Chemical Letters 2007, 18 (9), 1151. https://doi.org/10.1016/j.cclet.2007.07.031

[10] He L., Zhang S.F., Tang B.T. et al.: Chinese Journal of Chemical Engineering 2009, 17, 156. https://doi.org/10.1016/S1004-9541(09)60048-3

[11] Karst D., Yang Y.: Journal of Applied Polymer Science 2005, 96, 416. https://doi.org/10.1002/app.21456

[12] Karst D., Nama D., Yang Y.: Journal of Colloid and Interface Science 2007, 310, 106. http://dx.doi.org/10.1016/j.jcis.2007.01.037

[13] He L., Lu L., Zhang S.F., Freeman H.S.: Coloration Technology 2010, 126, 92. https://doi.org/10.1111/j.1478-4408.2010.00232.x

[14] Choi J-H, Lee H-Y., Towns A.D.: Fibers and Polymers 2010, 11, 199. http://dx.doi.org/10.1007/s12221-010-0199-1

[15] Hansakulwat P., Sae-Bae P., Setthayanond J., Na Phatthalung I.: Applied Mechanics and Materials 2014, 535,641 .

https://doi.org/10.4028/www.scientific.net/ AMM.535.641

[16] Cui Z., Guo J., Chen W., Tang B.T.: Advanced Materials Research 2012, 441, 503.

https://doi.org/10.4028/www.scientific.net/ AMR.441.503

[17] Cui Z., Wang X., Chen W. et al.: Coloration Technology 2012, 128, 283. https://doi.org/10.1111/j.1478-4408.2012.00376.x

[18] Lu L., Liang H., Zhang S., Freeman H.S.: Coloration Technology 2012, 128, 121. https://doi.org/10.1111/j.1478-4408.2011.00354.x

[19] Burkinshaw S.M., Jeong D.S.: Dyes and Pigments 2012, 92, 1025. https://doi.org/10.1016/j.dyepig.2011.06.020

[20] Choi J-H, Choi J-Y, Kim E-M. et al.: Coloration Technology 2013, 129, 352. https://doi.org/10.1111/cote.12037

[21] Ribba K., Goyanes S.: Material Letters 2016, 182, 94. http://dx.doi.org/10.1016/j.matlet.2016.06.090

[22] Tayfun U., Dogan M.: mPolymer Bulletin 2016, 73, 1581. http://dx.doi.org/10.1007/s00289-015-1564-4

[23] Baykuș O., Davulcu A., Dogan M.: Fibers and Polymers 2015, 16, 2558. http://dx.doi.org/10.1007/s12221-015-5613-2

[24] Baykuş O., Dogan S.D., Tayfun U. et al.: The Journal of The Textile Institute 2017, 108, 569. https://doi.org/10.1080/00405000.2016.1175536

[25] Baig G.A.: Coloration Technology 2012, 128, 114. https://doi.org/10.1111/j.1478-4408.2011.00353.x

[26] Sawada K., Ueda M.: Dyes and Pigments 2007, 74, 81. https://doi.org/10.1016/j.dyepig.2006.01.015

[27] Burkinshaw S.M., Jeong D.S., Chun T.I.: Dyes and Pigments 2013, 97, 361.

https://doi.org/10.1016/j.dyepig.2011.12.007
[28] Burkinshaw S.M., Jeong D.S., Chun T.I.: Dyes and Pigments 2013, 97, 374. https://doi.org/10.1016/j.dyepig.2012.12.026

[29] Koo G.-H., Jang J.: Fibers Polymers 2009, 9, 674. https://doi.org/10.1007/s12221-008-0106-1

[30] Baykuş O., Davulcu A., Dogan M.: Polymer Bulletin 2017, 12. https://doi.org/10.1007/s00289-017-2010-6

[31] Sriumaroum V., Liprapan S., Siriphet B. et al.: Advanced Materials Research 2011, 233-235, 1384. https://doi.org/10.4028/www.scientific.net/AMR.233235.1384

[32] Wu J., Ke J.: Advanced Materials Research 2011, $183-$ 185, 2000.

https://doi.org/10.4028/www.scientific.net/AMR.183185.2000

[33] Ujjin S., Jantip S.: Advanced Materials Research 2012, 486,384 .

https://doi.org/10.4028/www.scientific.net/ AMR.486.384

[34] Sriumaroum V., Suesat J., Suwanruji P.: International Journal of Bioscience, Biochemistry and Bioinformatics 2012, 2, 155

[35] Wu J., Guo H., Ke J., Fan J.: Indian Journal of Fibre \& Textile Research 2013, 38, 424.

[36] Sidarkote R., Suwanruji P., Suesat J.: Advanced Materials Research 2014, 1025-1026, 531.

https://doi.org/10.4028/www.scientific.net/ AMR.1025-1026.531

[37] Karim M.N., Afroj S., Rigout M. et al.: Dyes and Pigments 2014, 103, 168. https://doi.org/10.1016/j.dyepig.2013.12.010

[38] Karim M.N., Rigout M., Yeates S.G., Carr C.: Journal of Materials Science 2015, 50, 4576. http://dx.doi.org/10.1007/s10853-015-9006-0

[39] Xu S., Chen J., Chen I. et al.: Key Engineering Materials 2016, 671, 121.

https://doi.org/10.4028/www.scientific.net/ KEM.671.121

[40] Xu S., Chen J., Wang B., Yang Y.: Journal of Colloid and Interface Science 2015, 458, 22. http://dx.doi.org/10.1016/j.jcis.2015.07.028

[41] Fu Z., Huang H., Yu L. et al. Applied Mechanics and Materials 2013, 364, 660.

https://doi.org/10.4028/www.scientific.net/ AMM.364.660

[42] Hawkyard C.: "Synthetic Fiber Dyeing", S.D.C. Bradford 2004, p. 58.

[43] Phillips D., Suesat J., Taylor J.A. et al.: Coloration Technology 2004, 120, 260. https://doi.org/10.1111/j.1478-4408.2004.tb00128.x

[44] Baig G.A.: Fibers and Polymers 2013, 14, 1912. https://doi.org/10.1007/s12221-013-1912-7

[45] Suesat J.: PhD Thesis, University of Manchester, Manchester, UK 2004.

[46] Yang Y., Huda S.: "The balance between dyeing and physical properties of PLA", Proceedings of the AATCC 
International Conference and Exhibition 2002.

[47] Yang Y., Huda S.: Journal of Applied Polymer Science 2003, 90, 3285.

https://doi.org/10.1002/app.13062

[48] Yang Y., Huda S.: AATCC Review 2003, 3, 56.

[49] Nakamura T., Ishii K., Kubokawa H. et al.: "An overview on dyeing properties of polylactic acid (PLA) fiber", Proceedings of the AATCC International Conference and Exhibition, USA 2001.

[50] Nakamura T.: International Textile Bulletin 2003, 4, 68.

[51] Shore J.: "Colorants and Auxiliaries", $2^{\text {nd }}$ Edition, Vol. 2, SDC, Bradford, UK 2002.

[52] Kinashi K., Suzuki T., Yasunaga H. et al.: Dyes and Pigments 2017, 145, 444.

https://doi.org/10.1016/j.dyepig.2017.06.040

[53] Bach E., Knittel D., Schollmeyer E.: Coloration Technology 2006, 122, 252. https://doi.org/10.1111/j.1478-4408.2006.00037.x

[54] Wen H., Dai J.J.: Journal of Applied Polymer Science 2007, 105, 1903. https://doi.org/10.1002/app.26234

[55] Xu S., Chen J., Wang B., Yang Y.: ACS Sustainable Chemistry and Engineering 2015, 3, 1039. https://doi.org/10.1021/sc500767w

[56] Xu S., Chen J., Wang B., Yang Y.: Journal of Cleaner Production 2016, 112, 987. http://dx.doi.org/10.1016/j.jclepro.2015.08.114

[57] Choi H.J., Seo Y.W.: Fibers and Polymers 2006, 7, 270. https://doi.org/10.1007/BF02875684

[58] Choi H.J., Kim M., Park J. et al.: Fibers and Polymers 2007, 8, 37. https://doi.org/10.1007/BF02908157

[59] Blackburn R.S., Zhao X., Farrington D. W., Johnson L.: Dyes and Pigments 2006, 70, 251. https://doi.org/10.1016/j.dyepig.2005.05.011

[60] Fattahi F., Izadan H., Khoddami A.: Progress in Color, Colorants and Coatings 2012, 5, 15.

[61] Lunt J., Shafer A.L.: Journal of Industrial Textiles 2000, 29, 191. http://dx.doi.org/10.1177/152808370002900304

[62] Lunt J., Bone J.: AATCC Review 2001, 1, 20.

[63] Burkinshaw S.M., Jeong D.S.: Dyes and Pigments 2012, 92, 988. https://doi.org/10.1016/j.dyepig.2011.07.005

[64] Dugan J.S.: "Novel Properties of PLA Fibers, Research Fiber Innovation Technology", Inc., INTC 2001, pp. 9-33.

[65] Avinc O.: PhD Thesis, University of Manchester, UK 2007.

[66] Suesat J., Mungmeechai T., Suwanruji P. et al.: Coloration Technology 2011, 127, 217. https://doi.org/10.1111/j.1478-4408.2011.00301.x

[67] Reichardt C.: "Solvents and Solvent Effects in Organic Chemistry", $3^{\text {rd }}$ Ed., Weinheim: Wiley-VCH Verlag GmbH \& Co. KgaA, 2003, p. 330 .

[68] Avinc O., Phillips D., Wilding M.: Coloration Technology 2009, 125, 288. http://dx.doi.org/10.1111/j.1478-4408.2009.00209.x

[69] Mogi K., Negulescu T., Kubokawa H., Komatsu H.: Sen'i Gakkaishi 2001, 57, 234. https://doi.org/10.2115/fiber.57.234

[70] Mogi K., Nakamura T., Kubokawa H., Komatsu H.: Sen'i Gakkaishi 2001, 57, 239.

https://doi.org/10.2115/fiber.57.239

[71] Mogi K., Nakamura T., Kubokawa H., Komatsu H.: Sen'i Gakkaishi 2003, 59, 198.

https://doi.org/10.2115/fiber.59.198

[72] Avinc O., Wilding M., Bone J. et al.: Coloration Technology 2010, 126, 353. https://doi.org/10.1111/j.1478-4408.2010.00269.x

[73] Park Y.K., Jo A.R., Jang S.S., Lee J.J.: Coloration Technology 2016, 132, 361.

https://doi.org/10.1111/cote.12228

[74] Avinc O., Phillips D., Wilding M. et al.: Coloration Technology 2006, 122, 157.

https://doi.org/10.1111/j.1478-4408.2006.00023.x

[75] Burkinshaw S.M., Jeong D.: Dyes and Pigments 2008, $77,171$.

https://doi.org/10.1016/j.dyepig.2007.04.005

[76] Burkinshaw S.M., Jeong D.: Dyes and Pigments 2008, $77,180$.

https://doi.org/10.1016/j.dyepig.2007.05.010

[77] Burkinshaw S.M., Jeong D.S.: Dyes and Pigments 2008, 77, 387. https://doi.org/10.1016/j.dyepig.2007.06.006

[78] Avinc O.: Textile Research Journal 2011, 81, 1158. http://dx.doi.org/10.1177/0040517511402124

[79] Avinc O.: Textile Research Journal 2011, 81, 1049.

[80] Avinc O., Eren H.A., Uysal P.: Coloration Technology 2012, 128, 479. https://doi.org/10.1111/j.1478-4408.2012.00403

[81] Eren H.A., Avinc O., Uysal P., Wilding M.: Textile Research Journal 2011, 81, 1091.

[82] Eren H.A.: Coloration Technology 2007, 23, 224. https://doi.org/10.1111/j.1478-4408.2007.00087.x

[83] Eren H.A.: Coloration Technology 2006, 122, 329. https://doi.org/10.1111/j.1478-4408.2006.00049.x

[84] Eren H.A., Anis P.: "Examining the effectiveness of oxidative clearing in one-step dyeing of polyester/ cotton fabrics" $2^{\text {nd }}$, International Istanbul Textile Congress, Istanbul 2004.

[85] Gomes J.I.N.R, Lima C.J.E., Almeida J.R.: “Oxidative clearing of polyester as an alternative to reduction clearing: A comparative study", Proceedings of the AATCC International Conference and Exhibition, 2000, p. 1.

[86] Aleem A., Christie R.M.: Coloration Technology 2016, 132, 280.

https://doi.org/10.1111/cote.12217

Received 31 I 2020. 